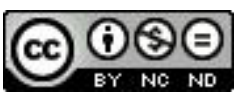

\title{
As Interações na Atividade de Resolução de Problemas e o Desenvolvimento da Capacidade de Comunicar no Ensino Básico
}

\section{Interactions in the Problem Solving Activity and the Development of the Communication Ability in the Basic Education}

\author{
Maria de Lurdes Serrazina* \\ Deolinda Ribeiro**
}

\begin{abstract}
Resumo
Este artigo relata parte de uma pesquisa que visou compreender que interações ocorrem na atividade de resolução de problemas capazes de desenvolver nos alunos, do $4 .^{\circ}$ ano do ensino básico, a capacidade de comunicar. Utilizou-se uma metodologia qualitativainterpretativa. A recolha de dados fez-se através de entrevistas, observação de aulas de resolução de problemas, registos dos alunos e notas de campo. A atividade de resolução de problemas permitiu que os alunos desenvolvessem a aptidão para explicitar oralmente o raciocínio utilizado e para representarem por escrito as ideias matemáticas, criando oportunidades para comunicarem entre si e com a professora na aula. A natureza e qualidade das interações comunicativas ocorridas variaram com a abordagem da resolução de problemas na sala de aula, tendo sido decisivas tanto as interações verticais, como as horizontais para os alunos se envolverem na atividade, criarem um espírito investigativo e desenvolverem a capacidade de comunicar.
\end{abstract}

\footnotetext{
"PhD, University of London. Professora coordenadora da Escola Superior de Educação do Instituto Politécnico de Lisboa, Lisboa, Portugal. Endereço para correspondência: Campus de Benfica do IPL, 1549-003 Lisboa, Portugal.E-mail: lurdess@eselx.ipl.pt.

*** Mestre, Universidade de Lisboa. Professora titular de uma turma do $1^{\circ}$ ano de escolaridade na Escola $N^{\circ} 1$ do Cacém, Agualva-Cacém, Sintra, Portugal. Endereço para correspondência: Avenida Maria Lamas, $\mathrm{n}^{\circ} 4,1^{\circ}$ esq., Serra das Minas, 2635-430. Rio de Mouro, Sintra, Portugal. E-mail: deolinda_eselx@hotmail.com.
} 
Palavras-chave: Resolução de Problemas. Interações Comunicativas. Comunicação. Aprendizagem. Papel do Professor e do Aluno.

\begin{abstract}
This article reports partially a research whose main goal was to understand which classroom interactions occur in the problem solving activity that are able to develop in 4th grade's pupils the ability to communicate. It was used a qualitative-interpretative methodology. The data collection was made by interviews, problem solving classroom observations, pupils' records and field notes. Problem solving activity allowed that pupils developed the aptitude to explain orally their used reasoning and to represent by writing their mathematical ideas, creating opportunities to pupils communicate among them and with the classroom teacher. It was verified that the nature and the quality of communicative interactions varied with the way of approaching problem solving in classroom. The vertical interactions as well as the horizontal ones were decisive to the pupils' involvement into the activity, the creation of pupils' investigative spirit and the development of pupils' communication ability.
\end{abstract}

Keywords: Problem Solving. Communicative Interaction. Communication. Learning. Teacher's Role. Pupil's Role.

\title{
1 Introdução
}

Desenvolver a capacidade de resolução de problemas, nos alunos, é considerada uma das principais finalidades do ensino da Matemática, que está, hoje, associada ao desenvolvimento da capacidade de comunicação. Entendendose por comunicação um processo social onde os intervenientes interagem, trocando informações, influenciando-se reciprocamente na construção de significados. Também o trabalho de grupo, como organização da sala de aula, tem sido defendido por diferentes organizações, realçando o papel da aprendizagem cooperativa no desenvolvimento da comunicação, da sociabilidade e da capacidade de resolução de problemas.

Este artigo tem por base um estudo (RIBEIRO, 2005) em que se procura compreender que interações ocorrem na atividade de resolução de problemas capazes de desenvolver nos alunos, do $4^{\circ}$ ano do ensino básico, a capacidade de comunicação. Após um breve enquadramento teórico, apresenta-se, sumariamente, a metodologia utilizada na pesquisa e expõe-se a forma como foi feita a abordagem da resolução de problemas na sala de aula. Em seguida, procura-se descrever, analisar e identificar o tipo de interações ocorridas na atividade de resolução de problemas. 


\section{Resolução de problemas}

A resolução de problemas como uma das experiências de aprendizagem fundamental no ensino da Matemática é uma ideia que tem vindo a ser fortalecida nas últimas décadas. A justificá-la, estão os resultados da crescente investigação em Educação Matemática, bem como o impacto social do desenvolvimento da tecnologia que coloca cada vez mais desafios ao professor, aos alunos e aos investigadores. Para fazer face a esses desafios, o professor deve propor tarefas de natureza muito diversa na aula de matemática: exercícios, problemas, investigações $^{1}$ e explorações (PONTE, 2005). Cabe-lhe diversificar as tarefas que propõe aos alunos, no sentido de incrementar uma educação matemática que facilite o desenvolvimento do pensamento matemático (SKOVSMOSE, 2000). O professor deverá fazer essa seleção, tendo em conta diversas condições, entre as quais as características de cada um dos tipos de tarefa, a capacidade e o interesse dos alunos e o modo de trabalhar na sala de aula (PONTE, 2004).

No ensino fundamental, resolução de problemas e investigações matemáticas correspondem a atividades que envolvem processos elaborados de pensamento. Tanto uma noção como outra referem-se a processos matemáticos complexos, e as duas envolvem atividades fortemente problemáticas (PONTE et al., 1998). Uma tarefa pode ser um problema para um indivíduo e não o ser para outro. Também, pode acontecer que a mesma tarefa seja um problema para um indivíduo, num dado momento e, à posteriori, apenas um exercício. Tudo depende dos conhecimentos que cada um possui no momento em que lhe é apresentada a tarefa ou do interesse que a mesma lhe suscita (FERNANDES, 1994; FONSECA, 2000; PONTE, 2003). A resolução de problemas é, assim, considerada uma situação de aprendizagem, em que o aluno se confronta com questões às quais não consegue responder de forma imediata, mas que o levam a refletir no como e no porquê, sempre na procura da solução. A posição adotada na pesquisa teve presente que o conceito de problema é sempre relativo ao sujeito a quem se destina (PONTE, 2003). Ser problema não é uma característica intrínseca de uma dada tarefa; depende, essencialmente, da relação que o aluno, potencial resolvedor, estabelece com ela. Num trabalho em que pretendera comunicar uma experiência pessoal de resolução de problemas, enquanto professor, Paulo Abrantes (1988, p. 52) escreveu que "de facto, a resolução de problemas consiste, acima de tudo, numa larga variedade de processos, atividades e experiências intelectuais" e não numa "atividade a

\footnotetext{
${ }^{1}$ Também designadas por atividades investigativas por J. P. Ponte et al. (1998).
} 
desenvolver apenas em paralelo ou à margem das atividades curriculares". Neste trabalho, os problemas são tarefas de natureza mais ou menos fechada, capazes de desafiar as capacidades e os interesses dos alunos.

\section{As interações e a comunicação na aprendizagem da matemática}

As orientações curriculares para o ensino básico em Portugal, particularmente as destinadas ao $1^{\circ}$ ciclo do ensino básico (os quatro primeiros anos do ensino fundamental), salientam, há muito, que todas as crianças devem aprender a gostar de Matemática, encarando-a como um desafio. Salientam, igualmente, o papel do professor na criação de um ambiente de trabalho ativo, repleto de experiências dinâmicas de aprendizagem, adequadas e variadas, indicando a resolução de problemas como um momento especial de interação e diálogo. Acrescentam, ainda, que uma das funções fundamentais do professor na sua interação com os alunos é saber ouvir, perguntar porquê, lançar pistas, aproveitar o erro para lançar novas perguntas e, também ,saber estimular essa atitude nos seus alunos (DEB, 1990), criando, assim, uma verdadeira atmosfera de aprendizagem onde todos interagem, trocando informações, influenciando-se reciprocamente.

Lampert e Cobb (2003) encaram a comunicação como objetivo curricular por um lado, ou seja, como conhecimento e compreensão matemática a desenvolver e, por outro, como meio ou parte de uma metodologia de ensino. A comunicação matemática está, portanto, ao serviço da aquisição de conhecimentos, mas também é parte integrante dessa mesma aprendizagem. Sai reforçada a ideia que, mais do que trocar informações, a comunicação se traduz na partilha e negociação de significados entre os interlocutores. Esta mesma ideia está expressa no actual Programa do Ensino Básico em Portugal (ME, 2007), onde a comunicação aparece como uma capacidade transversal, a par da Resolução de Problemas e do Raciocínio Matemático, mas também como um aspeto metodológico a considerar.

Para César (1999), as interações entre os alunos podem ser diversas. Elas podem manifestar-se desde a execução de tarefas com um par com quem não há comunicação verbal, até às situações em que o grupo de trabalho chega a um acordo sobre uma solução para um problema proposto. Roselli, Gimelli e Hechen (1995), referidos por Mamede (2001), consideram três modos de interação na sala de aula: 1) a egocêntrica, que origina o isolamento e a pouca participação nas atividades na aula e que se caracteriza por existirem poucas interações 
verbais provenientes de uma atitude individualista ou de uma dificuldade de relacionamento; 2) a assimétrica ou dependente, que ocorre entre indivíduos de níveis diferentes quanto à sua competência, ao seu estatuto social e ainda quanto ao papel que cada um assume durante a tarefa, supondo o domínio de um sobre o outro; 3) a simétrica ou igualitária que assenta na negociação recíproca em que um procura convencer o outro e onde se reconhecem contributos de ambas as partes.

As interações entre os intervenientes na sala de aula e a forma como partilham o modo de encarar os conceitos e processos matemáticos, os fazem evoluir e ajustar ao conhecimento caracterizado pelo currículo, são dois aspectos identificados na literatura (e. g., BISHOP; GOFFREE, 1986; YACKEL; COBB, 1996; PONTE; SERRAZINA, 2000), a considerar no estudo da comunicação na sala de aula. As interações sociais na sala de aula desempenham um papel fundamental na aprendizagem da Matemática, uma vez que, quer a interação professor-aluno ${ }^{2}$ quer a interação aluno-aluno ${ }^{3}$, influenciam a matemática que é aprendida e como é aprendida na escola (WOOD; MERKEL; UERKWITZ, 1996).

Do ponto de vista de Bishop e Goffree (1986) a comunicação é considerada um pilar essencial das aprendizagens matemáticas pela sua função decisiva para a construção de significados. É por intermédio da comunicação, através da troca de ideias, que os conhecimentos são partilhados por todos e entendidos por cada um. Isto é, se os interlocutores concordarem com a validade dos referentes, dos exemplos, das analogias e das conexões apresentadas durante a comunicação, podemos dizer que existe partilha e negociação do significado do conhecimento matemático. Segundo Ponte e Serrazina (2000) essa partilha é feita, principalmente, com recurso à linguagem oral acompanhada da gestual, mas também à linguagem escrita, icónica e a dramatizações. Na sala de aula, a comunicação envolve variados tipos de interações entre os intervenientes, umas mais apropriadas do que outras à instituição de um discurso matemático produtivo. Estes autores distinguem três modos fundamentais de comunicação entre dois ou mais intervenientes: a exposição, o questionamento e a discussão. No primeiro e no segundo modo, há apenas um interveniente que o concretiza e, no terceiro, há a participação de todos os intervenientes. Na exposição, um dos intervenientes, normalmente o professor, expõe uma ideia, descreve factos ou sistematiza trabalhos e todos podem fazer perguntas para se esclarecerem. No

\footnotetext{
2 Também desiganda por interação vertical (CÉSAR, 1999).

3 Também designada por interação horizontal (CÉSAR, 1999).
} 
questionamento, um dos intervenientes, geralmente o professor, faz perguntas consecutivas com objetivos definidos: detetar dificuldades na compreensão dos conceitos e dos processos matemáticos, ajudar a raciocinar, incentivar a participação e verificar se o trabalho da aula está a ser acompanhado.

Neste modo de comunicação, aqueles autores consideram três tipos de perguntas essenciais: as de focalização, que ajudam o aluno a percorrer um determinado raciocínio até completar a tarefa; as de confirmação, que ajudam o aluno a verificar as respostas por si próprio; e as de inquirição, que esclarecem o professor acerca do modo de pensar do aluno (como resolveu determinado problema ou que opinião tem sobre um resultado ou estratégia). O uso equilibrado que o professor faz dos tipos de perguntas depende da sua visão de ensino e de aprendizagem e do que entende ser o seu papel e o do aluno. A discussão, moderada pelo professor, tem como objetivo fomentar interações entre todos os intervenientes da aula, de modo a: definir a estratégia a seguir para a realização de uma tarefa, discutir o balanço do trabalho ou a avaliação de uma solução. Com este modo de comunicação, espera-se que tanto professor como alunos desenvolvam, cooperativamente, as ideias e o pensamento matemático, e que o envolvimento dos alunos na sua aprendizagem seja mais ativo. Para tal, o professor deve: explorar as sugestões dos alunos, ajudá-los a avaliar e a refletir sobre as sugestões dos colegas, levantando dúvidas e implicações ou hipóteses; encaminhar a comunicação para que os alunos oiçam, respondam, comentem e usem argumentos matemáticos para determinar a validade de afirmações, convencendo e convencendo-se. Ou seja, "para uma melhor prática de ensino da Matemática é necessário envolver o professor e os alunos na prática de questionamento e de reflexão" (GUERREIRO, 2011, p. 99).

\section{Metodologia}

Como referido, neste artigo relata-se parte de um trabalho mais amplo, que contou com a colaboração de uma professora, também designada por Ana (nome fictício), e dos seus alunos do $4 .^{\circ}$ ano do ensino básico. O trabalho desenvolveu-se em pequenos grupos, por se considerar esta organização mais favorável a uma maior participação dos alunos, nomeadamente, quando exprimem as suas ideias e comentam as dos colegas. De entre os grupos foi selecionado um, composto por quatro elementos, duas raparigas, Bela e Sara, e dois rapazes, Daniel e Tomás (nomes fictícios), sobre o qual incidiu a recolha dos dados. A seleção e a composição do grupo foi feita pela professora, que melhor conhecia 
os alunos e teve em atenção: i) ter igual número de rapazes e raparigas; ii) ser heterogéneo em termos de competência matemática e de capacidade comunicativa dos alunos.

Toda a recolha de dados foi realizada pela segunda autora, e iniciou-se com entrevistas iniciais à professora e a cada um dos quatro alunos, registadas em áudio e transcritas. As aulas de resolução de problemas foram observadas (com base num guião de observação) e gravadas em áudio e vídeo. Foram, ainda, recolhidos os registos escritos dos alunos das resoluções dos problemas.

A partir das transcrições das aulas e dos guiões de observação foi realizada a análise da atividade de resolução de problemas. Nesta análise atendeuse ao modo como foi feita a abordagem de resolução de problemas na sala de aula: 1) apresentação e introdução da proposta de trabalho, pela professora, a toda a turma; 2) resolução do problema pelo grupo dos quatro alunos (Bela, Daniel, Sara e Tomás) e 3) comunicação dos caminhos/estratégias encontrados (as) por cada grupo em plenário de turma. Os outros alunos que são citados na análise (Flávio, Jacira, Manuel, Mara, Mónica, Pedro e Sandra (nomes fictícios)) faziam parte dos outros grupos da turma e tiveram alguma interação durante a discussão na turma dos problemas selecionados. Os dados foram agrupados em três grandes categorias: aprendizagem, interações e comunicação.

Este artigo analisa duas das seis aulas de resolução de problemas. A primeira corresponde à terceira proposta feita à classe, durante a pesquisa, e a segunda corresponde à sexta e última. Com elas procura-se caracterizar o tipo de interações capazes de contribuir para o desenvolvimento da capacidade de comunicar no ensino fundamental, questão que serviu de motivação inicial à realização da pesquisa.

\section{A abordagem à resolução de problemas na sala de aula}

$\mathrm{Na}$ apresentação e introdução, a professora Ana procurava motivar os alunos para o trabalho, dialogando com eles sobre situações do seu dia-a-dia relacionadas com a tarefa a propor. De seguida, usualmente, lia-a em voz alta, interrompendo a leitura para tornar mais claras expressões que apareciam no texto, esclarecendo dúvidas, de modo a que o problema fosse compreendido por todos.

No trabalho em pequenos grupos, os alunos, colaborativamente, encontravam respostas para os problemas propostos. Durante a atividade dos alunos, Ana circulava por entre os grupos, observando e intervindo sempre que 
era solicitada ou achava oportuno. Depois do problema resolvido, os porta-vozes dos grupos mostravam como tinham encontrado uma solução para o problema e discutiam-se estratégias e resultados. Aqui, Ana ajudava os alunos com mais dificuldade na verbalização das ideias ou na clarificação dos seus pensamentos. No final das comunicações feitas pelos alunos, Ana apresentava, também ela, a resolução do problema, usando outro tipo de estratégia ou um modelo mais abstrato.

As interações comunicativas na resolução da tarefa $\mathrm{Na}$ pizaria

Na pizaria, é uma tarefa composta por um enunciado muito simples, como se pode ver no Quadro 1, mas pouco estruturado, em que o vocabulário usado pode ter influenciado o desempenho dos alunos no primeiro contacto com o problema.

\section{NA PIZARIA}

Na pizaria do Sr. André há um anúncio:

"Mais de 20 pizas diferentes"

Sabendo que se fazem pizas até 5 ingredientes, digam se o anúncio é verdadeiro.

\section{Quadro 1 - Tarefa na pizaria}

A professora iniciou a primeira parte da atividade, criando um ambiente de expetativa na turma, dialogando com os alunos sobre situações da vida do dia-a-dia, tais como anúncios e publicidade enganosa. A tarefa foi primeiro apresentada oralmente e depois por escrito. Essa apresentação foi feita de modo expositivo, através da leitura do enunciado. Em seguida, os alunos responderam a perguntas de focalização que visavam detetar dificuldades na compreensão do enunciado:

\footnotetext{
Prof. a - O anúncio é o que está ...entre ....aspas. [Continua a leitura até ao final]... "mais de 20 pizas diferentes". O que é que isto quer dizer aos clientes? Quem passa e lê, o que é que interpreta com esta frase? Que...naquela pizaria... Vários alunos- Há mais pizas diferentes.
}

Foram, também, colocadas questões de confirmação, para ajudar os alunos na interpretação do que era proposto e para concentrar a sua atenção nos aspetos essenciais da situação: 
Prof. ${ }^{\text {a }}$ - Então continuam a concordar com o Manuel que são pizas que não podem levar mais de 5 [ingredientes]. Mas podem levar 5 ?

Jacira, Bela e Mónica- Podem.

Prof. ${ }^{\text {- }}$ Todos concordam que podem? E só podem levar 5?! Mónica- sim.

Manuel- Ou então, 4,3,2,1...tanto faz...

Nesta primeira parte da aula também se verificaram perguntas de inquirição por parte da professora, que visaram esclarecê-la acerca do que pensava o aluno da expressão pizas diferentes com cinco ingredientes:

Pedro- Ó professora podem levar um ingrediente ou mais, até 5.

Prof.'- O que é isso "ou mais" explica-te melhor.

Pedro- Às vezes só podem pôr 1,2,3,4 ou 5...

Prof. ${ }^{a}$ - Na mesma, ou em diferentes pizas?

Pedro- Na mesma.

A legitimação das ideias expressas pelos alunos era remetida aos grupos para que as resolvessem na segunda parte da aula, incentivando as interações horizontais no grupo. Na primeira parte da atividade não chegaram a verificarse interações horizontais. Os alunos tendiam a solicitar a validação das suas ideias junto da professora, e, se isso não fosse feito, mostravam-se mais inseguros.

$\mathrm{Na}$ segunda parte da aula, as interações horizontais ocorridas no grupo em estudo, não conduziram a um trabalho cooperativo produtivo, na medida em que não existiu cooperação entre os elementos do grupo. Inicialmente, as interações verbais entre todos os elementos, limitaram-se a que cada um mostrasse o seu plano de resolução do problema:

Daniel- Vou desenhar 20!

Bela- Puxa! Estás passado ou quê?

Tomás- Estava a pensar fazer uma piza e depois os ingredientes.

Bela- Eu faço uma piza e depois faço uma seta a dizer 20.

Daniel- Sabes porque é que eu vou ter que desenhar as pizas? Porque vou ter que desenhar em cima o que eu vou por nelas!

Como se depreende, as interações verbais conduziram a um trabalho pouco produtivo para as meninas do grupo, que logo que solicitaram ajuda 
perguntando: - temos de fazer 20 ingredientes, Daniel? -; receberam como resposta: - espera aí, só estou aqui a tentar fazer uma coisa!

Esta atitude mais individualista dos alunos, que se traduziu na conceção e execução de um plano de resolução individual para o problema, para só ser comunicado aos restantes elementos do grupo se der certo, fez salientar dois aspetos: primeiro, a necessidade de cada um dos alunos refletir, individualmente, sobre o seu próprio pensamento, tentando torná-lo mais claro para si antes de o apresentar ao grupo; segundo, os alunos ainda não aprenderam a definir estratégias, em grupo.

Também, se verificou que ao interagirem Daniel, Sara e Bela abandonaram o seu pensamento, não conseguindo argumentar perante um colega cuja competência matemática era reconhecida por todos:

Daniel- Ehhhh! Nós não temos de ter só 5 ingredientes! Só temos de fazer pizas com 5 ingredientes, não?

Sara- E com menos... di-fe-ren-tes. 5, di-fe-ren-tes.

Daniel- [leu de novo] ah! Então posso fazer mais, não é preciso só fazer estes!

Bela- Não... até! Daniel, até cinco!

Sara- Pois, pode ser com três, pode ser com dois, pode ser com um pode ser com 4.

Daniel- Sim, mas eu posso ter muito mais. Eu posso ter mil!

Só não posso ter mais de 5 ingredientes nas pizas!

Sara- Ahhh!

Existiram, também, momentos de interação simétrica que conduziram Daniel à solução do problema:

Tomás- Ainda não fiz com quatro...ingredientes!

Sara- Ham?

Tomás- Ainda não fiz com quatro ingredientes.

Daniel- Vais ter de fazer a piza com todos!

[Pausa]

Daniel- Ah yá... eu não preciso de... obrigada...eu não preciso de fazer seis ingredientes. Só preciso de fazer cinco!

Grande parte das interações entre os alunos foram realizadas de modo egocêntrico, caracterizadas por pouca verbalização das ideias e por um isolamento das atividades do grupo. Verificaram-se, ainda, interações verticais através de questões de focalização, fechadas e de resposta curta, que procuraram ajudar as alunas do grupo a ultrapassar as suas dúvidas e a envolverem-se na tarefa: 
Prof. a- O anúncio diz "mais de 20 pizas diferentes". Já conseguiste provar se com esses 5 ingredientes fazes mais de 20 diferentes ou menos? Neste momento, o que eu vejo aí é que tu com os cinco ingredientes fizeste uma. Não provaste nada, ainda.

Bela- Pois não!

Prof. ${ }^{a}-$ Tu tens que usar sempre os cinco [ingredientes]?

Bela- Não! Agora posso fazer com 3.

Prof. ${ }^{a}$ - Então vá, com três!

Observou-se, ainda, que os alunos foram apoiados pela professora, que assumiu o papel de orientadora, tendo a organização da discussão das estratégias apresentadas na terceira parte da atividade ficado totalmente a seu cargo. A professora, de um modo afirmativo, tentava tornar mais claras as afirmações dos alunos, fazendo perguntas de focalização:

Mara- Depois começámos a fazer as de 4 ingredientes. Íamos à legenda ver se já tínhamos posto. E acabámos por pôr a de 5.

Prof. ${ }^{a}$ - Então, quantas fizeram?

Mara- 26.

Prof. ${ }^{a}$ - Então o anúncio era verdadeiro ou falso?

Mara- Era verdadeiro porque tinha mais do que 20 pizas.

Prof. ${ }^{a}$ - Muito bem... chegaram à conclusão que era verdadeiro porque conseguiram fazer 26 pizas diferentes.

Ana encara os diferentes tipos de interação, a comunicação e a discussão dos resultados pelos alunos como fundamental no processo de aprendizagem. E, embora tenha consciência de que nem sempre o faz da melhor forma, não deixa de apostar na utilização de uma linguagem matemática que possa ser compreendida pelos vários intervenientes. Pois, sabe que a apropriação da linguagem matemática própria advém da relação que se estabelece entre a linguagem informal do mundo real da criança e a terminologia formal, característica da Matemática (ver Figura 1):

Tomás- Desenhámos as 20 e fomos metendo... os ingredientes.

Prof. ${ }^{a}$ - Fizeram por símbolos matemáticos, não foi?

Tomás- Foi, mas não são iguais... os ingredientes.

Prof. a - Tudo bem, mas usaram os símbolos, não foi? Explica lá.

Tomás- Na primeira piza... 
Prof. ${ }^{\text {a }}$ - Espera, primeiro escolheram os símbolos, não foi? Formas geométricas. Aqui está a legenda com os símbolos dos ingredientes que eles escolheram: o triângulo...

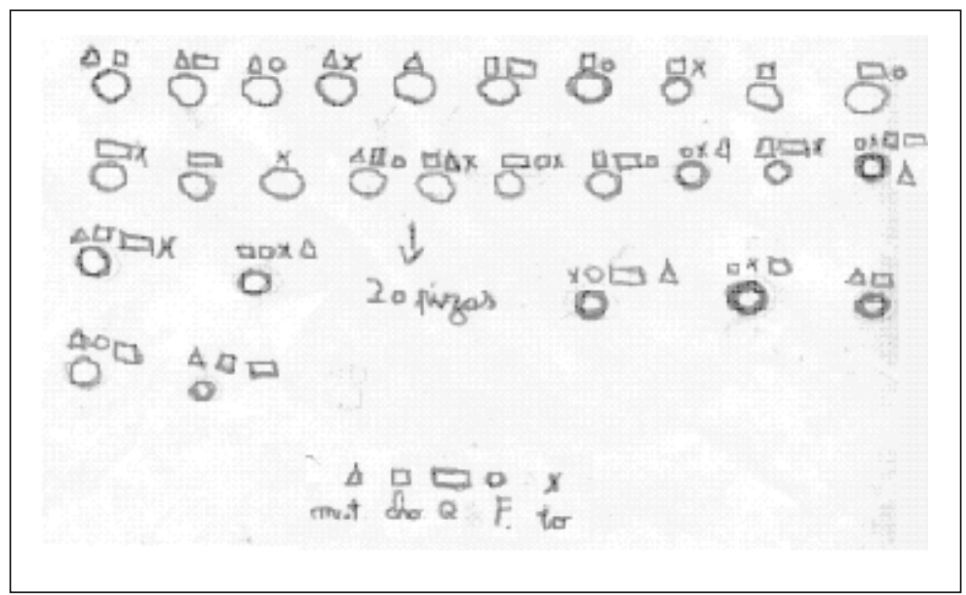

Figura 1 - Estratégia utilizada por Daniel e por Tomás

A professora teve, ainda, a preocupação de incentivar os alunos a observarem criticamente os resultados que, à partida, não estavam totalmente corretos, conduzindo e controlando a comunicação:

Prof. ${ }^{2}$ - Então, o que é que se passa agora, Jacira?

Jacira- Agora... há pizas repetidas.

Prof. ${ }^{a}$ - Será que o grupo pode dizer se o anúncio é verdadeiro ou falso?

Vários alunos- Não.

Prof. ${ }^{\text {- }}$ - De que precisavam, para conseguir dizer isso?

Jacira- Primeiro, ver se temos mais repetidas e depois, fazer as pizas que faltam.

Para concluir a atividade, Ana, de um modo afirmativo, sintetizou as comunicações feitas pelos alunos, elogiando a forma como alguns grupos tinham trabalhado colaborativamente. Realçou, também, a necessidade de cada um de nós respeitar os colegas e de resistir aos sentimentos de frustração para se obter sucesso na nossa vida em sociedade. Finalmente, apresentou a sua estratégia: um quadro onde estavam registadas todas as possibilidades/ combinações possíveis com cinco letras (ver Quadro 2): 
Prof. $^{\text {a }-~ R e p a r e m, ~ e s c o l h e m o s ~ p a r a ~ a s ~ n o s s a s ~ p i z a s ~ o s ~}$ ingredientes A,B,C,D,e E. Na linha de cima está a quantidade de ingredientes (...) Ao todo posso fazer 31 pizas diferentes com 5 ingredientes, uma vez que não podemos considerar só a massa como uma piza. Agora, tudo isto está certo matematicamente falando, porque na realidade quem é que vai pedir uma piza que só tenha a a massa e um ingrediente?! Concluindo: se o anúncio fosse "mais de 30 pizas diferentes", também seria verdadeiro, porque se conseguem fazer 31 .

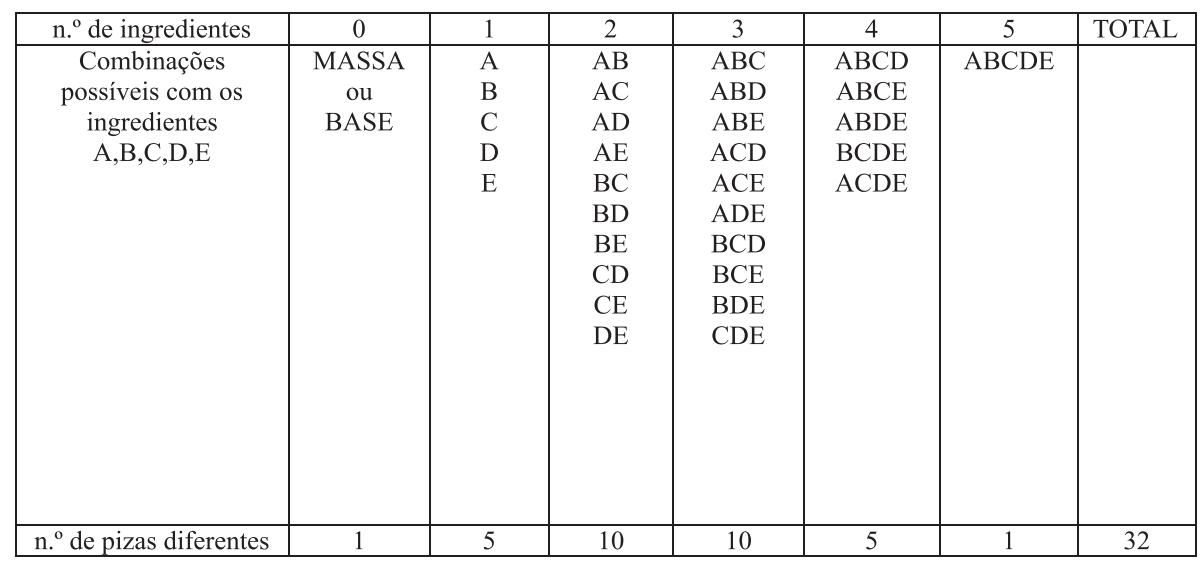

Quadro 2 - Estratégia apresentada pela professora para encontrar o número total de pizas

Contudo, e talvez porque já decorrera, aproximadamente, três horas de atividade, foi com alguma rapidez que fez a sua leitura, dando como terminada a atividade.

As interações comunicativas na resolução da tarefa: Tabela de preços

Para resolverem a tarefa Tabela de preços (ver Quadro 3), os alunos foram convidados a criar um ou mais problemas matemáticos a partir de uma situação artificial — uma tabela de preços de um parque de campismo — e, a resolver um deles.

A primeira parte da aula resumiu-se a um breve diálogo entre professora e alunos, sobre férias em parques de campismo e o funcionamento destes. A conversa não foi demorada, para se evitar desviar a atenção dos alunos da tarefa proposta. Ana leu e salientou alguns aspetos que os alunos deveriam 
observar na tabela de preços. Desse modo, as interações verticais professoraalunos serviram para informar e partilhar significados acerca da tarefa a desenvolver.

\section{TABELA DE PREÇOS}

Esta é a tabela de preços de um parque de campismo.

Qualquer um de nós pode ir lá passar uns dias.

Observem com atenção a tabela de preços e inventem um ou mais problemas matemáticos utilizando os dados desta tabela:

\begin{tabular}{|c|}
\hline Preços por dia \\
\hline Tenda grande (4 pessoas) .......... \\
\hline Tenda pequena ( 2 pessoas $)$. \\
\hline ......3 euros \\
\hline 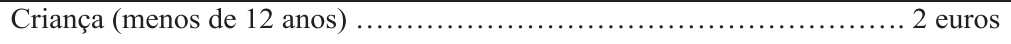 \\
\hline .............. 1 euro \\
\hline Animal de estimação .. \\
\hline
\end{tabular}

Quadro 3 - Tarefa Tabela de preços

As interações horizontais tiveram lugar apenas na segunda parte da atividade, enquanto os alunos trabalhavam em grupo. Ao iniciar a atividade, os alunos do grupo em estudo interagiram de forma concordante. Isto levou a um trabalho colaborativo produtivo, onde Daniel fez questão de marcar a sua liderança:

Daniel- Ah! Yá! Podia ir a turma toda a esse parque de campismo!

Bela- Sozinhos?

Daniel- Achas!? Quem é que faz parte desta turma?

Bela- A professora.

Daniel- ...e nós.

Sara- Yá! É fixe!

Os alunos responderam, ainda, a questões fechadas, e escutaram a exposição da professora que procurava apoiá-los nas suas ideias. Assim, a professora interagiu assimetricamente com os alunos, procurando saber o que pensavam fazer, ajudando-os a clarificarem melhor as suas ideias e a decidirem o contexto do problema a criar:

Prof. ${ }^{\text {a }}$ - Mas, vocês escolheram passar férias com a família ou escolheram ir numa visita de estudo da escola?

Sara- Numa visita de estudo. Fica melhor! 
Prof. ${ }^{\text {a }}$ - Têm que definir. São coisas diferentes! Se vocês escolherem passar férias com a família, está bem. Continuem assim. Se não... podem ir simplesmente acampar numa visita de estudo.

Sara- Sim professora, sem pais!

Bela- Eu acho que ficava melhor.

A professora incentivou o registo escrito como forma de anotar as ideias que iam definindo e decidindo em conjunto: - Não se esqueçam de escrever isso que estão a dizer: quem vai, o que leva... senão, depois não se sabe! Escrevam todas as vossas decisões.

Através de interações horizontais, Daniel tentava convencer os outros elementos do grupo da verdade das suas ideias, liderando de uma forma autoritária a atividade:

Daniel- Cala-te!...20, afinal somos 20!.

Bela- Estás a contar com quem?

Daniel- Com a professora. Nós somos 19 com a professora: 20.

Sara- Nós somos 19? Desde quando?

Daniel- Conta lá. Olha: 1,2,3,..19 [conta um a um todos os alunos da sala, em voz alta].

Sara- Ah! Pois é!

Nesta parte da aula, as iniciativas de interação com a professora, por parte dos alunos, tiveram como origem o pedido de esclarecimentos ou a resolução de pequenos conflitos que surgiram no grupo. Nessa sequência, aconteceu o questionamento sob a forma de inquirição ao aluno que tinha uma atitude mais individualista na atividade. Essas questões visaram permitir um melhor relacionamento entre os elementos do grupo, mas, também, que a explicitação do pensamento do aluno pudesse ajudar os outros. A professora exigiu correção na linguagem escrita, dada a sua qualidade de professora generalista, porém, essa correção foi, por vezes, imediata, não dando oportunidade ao aluno de explicitar o seu raciocínio:

Daniel- Aqui pus as tendas. As raparigas alugaram duas tendas, por isso tiveram que pagar 14 euros juntas e a professora.

Prof. ${ }^{a}$ - Mas aqui era já para resolver o problema? Ah, já tens a pergunta! [Lê] "quanto dinheiro tinham de pagar?" quanto dinheiro, eu não gosto desta construção frásica! Que dinheiro tinham de pagar ou quanto tinham de pagar... 
Sempre que os registos dos alunos se mostravam incompletos por falta de dados ou quando era necessária uma clarificação das ideias, Ana procurava dar sugestões aos alunos, orientando-os na formulação (ver Figura 2) e resolução do problema criado, através de perguntas de focalização. Nem sempre foi fácil para ela encontrar um limite para as orientações a dar, tendo, a determinada altura, apercebido-se que estaria a direcionar em excesso o pensamento dos alunos, encorajando a comunicação entre eles:

Prof. a- Mas não está aqui explicado! Aqui em baixo vocês deviam pôr quantos rapazes tem a turma, quantas raparigas tem. Eu estou a perceber o que querem dizer, mas eles [Bela e Tomás] não! [Olha para todos e continua] Ora vocês aqui em baixo vão pôr primeiro quem vai. Quais são as raparigas, quais são os rapazes, quais são os adultos... Se vão homens, se vão mulheres... Porque os homens não vão dormir com as mulheres, nem as raparigas com os rapazes na mesma tenda. Vá, conversem entre vocês.

Também nas interações horizontais se verificaram situações de questionamento para ultrapassar dúvidas e uma melhor compreensão do processo:

Sara- 8?! Agora são 8 raparigas?! Elas são 7. Ó Daniel, não conta com a professora. A professora não é rapariga, é adulta!

Daniel-Sim, uma adulta.

Sara- Então porque é que está aqui 8 , se somos 7 ?

[Daniel faz uma expressão de quem não vê dificuldade e não responde.] 


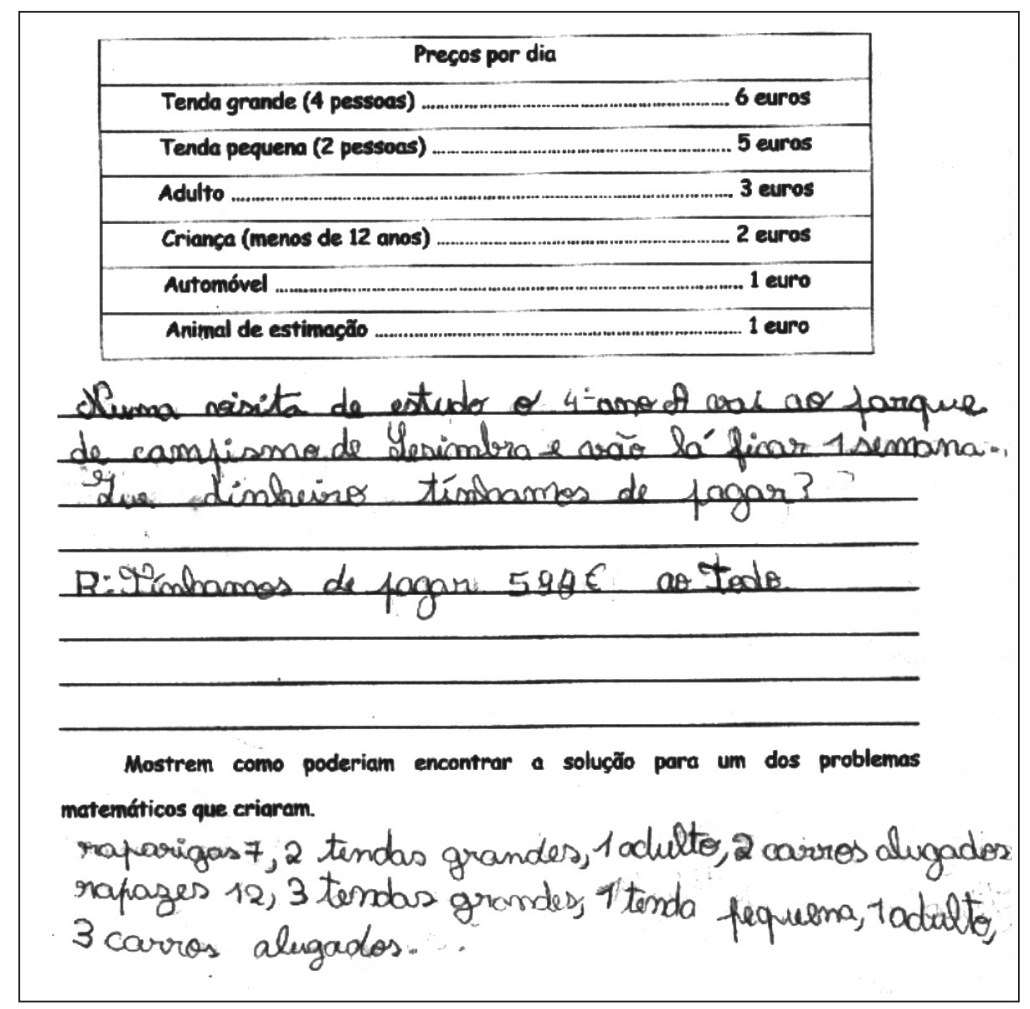

Figura 2 -Formulação de um problema efectuada pelo grupo em foco

Depois de Bela ter dito a Daniel que este não estava a trabalhar em grupo, e das duas colegas lhe terem feito ver que isso não era justo, Daniel resolveu explicar o seu plano, partilhando os significados do que ia sendo registado:

Daniel- Bem, eu aqui escrevi: 2 tendas para elas, grandes. Uma adulta e são sete crianças e 2 carros alugados que vocês não podem ir a conduzir, não é?

Bela- Mas explica-me uma coisa: repete isso tudo outra vez, que eu não percebi nada.

Daniel- Já fiz quantas raparigas são. Tem uma adulta que é a professora... vocês são 7 crianças e 12 crianças que somos nós...

Entretanto, Ana decidiu orientar os alunos para a resolução do problema através de perguntas de focalização: 
Prof. ${ }^{\text {a }}$ Olhem, e nessas tendas cabem todos a dormir?... Afinal quem vai?

Sara- E o adulto para os rapazes, professora?

Prof ${ }^{\text {a }}$ E um adulto... À frente... [afasta-se]

Tomás- $\mathrm{O}$ meu pai pode ir...

Bela- Professora, os pais podem ir?!

Prof ${ }^{\text {a }}$ - Claro que os pais podem ir!

Daniel- Assim temos de pôr mais uma tenda pequena.

Prof $^{\text {a }}$ - E quanto tempo vão ficar?

Sara- Uma semana...

Daniel-Uma semana.

Prof $^{\text {a }}$ - Não se esqueçam de registar o tempo que vão lá passar.

Quando o momento da produção dos alunos terminou, e para proceder à verificação dos passos do problema, Ana colocou perguntas de confirmação para levar os alunos a interiorizar melhor as ideias, utilizando, sobretudo, questões fechadas e de resposta curta ou questões para completar:

Prof. a - Que tendas?

Daniel- Tendas grandes.

Prof. ${ }^{\text {a }}$ Quantas tendas grandes foram?

Daniel- 5. E uma pequena.

Prof. ${ }^{\text {- }}$ Foram 5 tendas grandes. Então, é 5 vezes...

Daniel- ...6, dá 30 .

Observando que os alunos não tinham registado um dos dados: uma tenda pequena, Ana levou-os a descobrir o que faltava e a corrigir esse erro, para dar resposta ao problema:

Prof. a - Não vos falta nada?

Daniel- Não...

Prof. ${ }^{\text {- }}$ - Têm a certeza?

Sara- Falta a tenda pequena!

O diálogo entre Sara e Daniel começava a fluir. Sara percebera o dado em falta e Daniel verbalizava todo o raciocínio necessário para completar o trabalho:

Sara- Esquecemo-nos de quanto custa a tenda pequena.

Daniel- 5 euros a tenda pequena.

Sara- Então aqui [na legenda] falta-nos mais o 5.

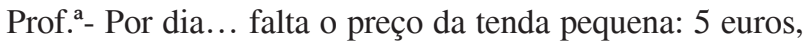


por dia...

Daniel- Ah, yá! 7 vezes 5... trinta e cinco. 35 numa semana

Daniel e Sara começaram a interagir de forma igualitária, já que ele verbalizava o procedimento algorítmico e Sara efetuava-o, dado ser quem melhor sabia os factos básicos da tabuada:

Sara- 553. É mais ou não, Bela?

Daniel- 553 também. Agora, para não se apagar nada, põe-se o 35 aqui [escreve 35 debaixo de 553].

Sara- ham...ham... [concordando]

A terceira parte da atividade foi um momento muito importante na aula. Os intervenientes colocaram em comum os resultados alcançados, e discutiram o trabalho realizado, ainda que de uma forma tímida. Cada grupo, na pessoa do seu porta-voz, apresentou o seu trabalho, pondo em comum resultados e significados, sendo por vezes avaliado por um elemento do mesmo grupo:

Mónica- Escrevemos a família do Flávio, a família do Pedro, a família do Dario, a minha família e a família da Sandra. Depois começámos a ver quantas tendas é que era preciso e o preço; quantos adultos é que eram e quantas crianças e quantos automóveis, depois eram 5 semanas, as férias, e o preço de um dia era 11 euros e o preço das 5 semanas era igual a 35 dias, então o avô do Flávio ia pagar 385 euros por 35 dias, 11 euros por dia. Depois a família do Pedro: fizemos quantas tendas é que eram, o preço, quantos adultos, quantas crianças e dois gatos e dois carros. Fizemos o preço do dia e a família do Pedro vai pagar 31 euros por $35 .$.

Flávio- Não. É 1085. Falta a conta de vezes.

Nesta parte, a professora assumiu o papel de orientadora, dirigindo a apresentação dos resultados, apoiando e deixando apoiar os alunos que se manifestavam inseguros:

Prof. - Sabes pois! A família da Sandra... o que é que ela levou?

Pedro- Levou...tenda grande.

Sandra- Uma!

Pedro- Uma tenda grande, iam dois adultos, duas crianças e um automóvel.

Prof. ${ }^{\text {a }}$ - Juntaram isto tudo e iam...

Pedro- ... pagar 17 euros... por dia. 
Após esta apresentação, a turma teve oportunidade de se expressar acerca do trabalho do grupo ou de colocar questões. Mas, como nenhum aluno avançou com nenhuma pergunta ou comentário, a professora colocou à portavoz do grupo uma pergunta de inquirição. A resposta mostra ter havido consenso na negociação da formulação do problema no grupo:

Prof. ${ }^{a}$ - Como é que decidiram que famílias iam aqui pôr?

Que história foi a vossa para formular o problema?

Mónica- A gente primeiro resolveu inventar as famílias, mas depois o Flávio deu uma ideia e a Sandra [também], que foi fazermos das nossas famílias, e a gente resolveu fazê-las.

Prof. ${ }^{\text {- }}$ Sim senhora, foi um bonita ideia. Posso passar à próxima?

\begin{tabular}{|c|}
\hline Preços por dia \\
\hline Tenda grande (4 pessoas) ............ \\
\hline Tenda pequena ( 2 pessoas)............ \\
\hline 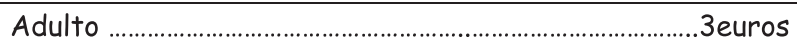 \\
\hline 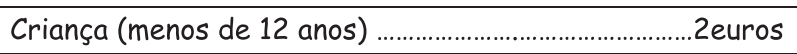 \\
\hline 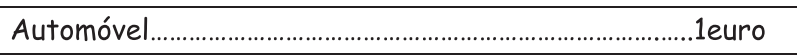 \\
\hline Animal de estimação \\
\hline
\end{tabular}

Fomos para férias ao parque de campismo.

Nós somos 4 crianças, 2 adultos, 2 animais o cão $e$

o gato. Nós ficamos sete dias no parque de campismo.

Vamos levar 3 tendas, uma tenda grande e duas tendas pequenas.

Quantos euros nós vamos gastar?

Mostrem como poderiam encontrar a solução para um dos problemas matemáticos que criaram.

$$
\begin{aligned}
& 2 \mathrm{x} 7=2 € \longrightarrow \text { animais } \quad 10 \quad 2+6+10+10+7+4=39 \\
& 2 \times 3=6 € \rightarrow \text { adultos } \quad 10 \\
& 5 \times 2=10 € \longrightarrow \text { crianças } 7 \\
& 2 \times 5=10 € \rightarrow \text { t.pequenas } 6 \\
& 7 \times 7=7 € \longrightarrow \text { automóvel } 4 \\
& 7 \times 4=4 € \rightarrow \text { t.grande } \frac{+2}{39 €}
\end{aligned}
$$

Figura 3 - Formulação e resolução do problema efetuadas pelo grupo de Mara 
Numa outra apresentação, ao partilhar os significados da representação simbólica utilizada para resolver o problema criado, a aluna deixou de conseguir fazê-lo. A representação (ver Figura 3) tornara-se incompreensível e, portanto, impossível de partilhar:

Mara- Depois era $4 \times 4 \ldots$ (corrigiu) $4 \times 7 \ldots$ Não!

Prof. a - $\mathrm{O}$ automóvel era um euro...o automóvel vezes sete...

Ela enganou-se, espera... Então, o automóvel era um euro, se eles levavam um automóvel...

Mara- Não professora, era um euro vezes sete.

Prof. ${ }^{\text {a }}$ - Uma vez sete? Ora deixa ver, a tenda grande está bem [não está!]. A tenda grande e a tenda pequena. Este um é um animal de estimação, não é?

Mara-Sim, professora.

Foi a própria aluna que deu significado à expressão que lhe sugeria dúvidas:

Mara- Professora, nós íamos meter $1 \times 7$ que dava sete porque eram sete dias que nós íamos lá passar e pagávamos 1 euro [por dia].

Em seguida, Ana sintetizou o raciocínio que o grupo deveria ter seguido, não colocando mais questões.

Prof. ${ }^{a}$ - Ah! Pois é, a Mara tem razão! Mas, repara que assim só o automóvel é que pagou sete dias! Esqueceram-se de pôr os animais, 7 dias: 7 vezes; os adultos 7 vezes; as crianças 7 vezes; a tenda pequena e a tenda grande 7 vezes.

De notar que, após esta apresentação, foi colocada uma questão por uma aluna. A professora remeteu a resposta para o grupo, estimulando a interação horizontal. Para a professora, a comunicação gerida por si é muito importante no processo de ensino-aprendizagem, por isso, é ela quem incentiva os alunos a comunicarem uns com os outros, utilizando uma linguagem compreensível para todos, na clarificação dos raciocínios:

Sandra- O que é isso? [apontando para o algoritmo da adição]

Prof. ${ }^{a}$ - Ó Manuel, explica lá à Sandra o que quer dizer esse algoritmo.

Manuel- É o resultado que nos deu em tudo o que nós pagámos...

Prof. ${ }^{\text {a }}$ - Olha, estás a ver aqui os cálculos: 10 euros, 10 euros, 7 euros, 6 euros, 4 euros e 2 euros. O total seria a quantia que deveriam pagar por dia. Estás a perceber? 
Nesta parte da atividade, Ana deu muita importância à partilha e negociação dos significados, mas também colocou aos alunos perguntas de confirmação fechadas que interromperam a apresentação ou iniciaram a resposta, como foi no caso da apresentação do trabalho do grupo em estudo:

Tomás- Os rapazes eram 12. Tivemos de ficar com 3 tendas grandes e uma pequena...

Prof. ${ }^{a}$ - Porque é que é preciso uma tenda pequena?

Tomás- É para o meu pai ficar connosco.

Prof. ${ }^{\text {- }}$ É para este adulto aqui? Por acaso escolheram o teu pai, foi? Então os rapazes iam todos...

Tomás- Em 3 carros alugados.

A sua intencionalidade era conduzir os alunos à avaliação e à reflexão crítica dos passos dados pelo grupo na formulação e resolução do problema (ver Figura 4) e, ao mesmo tempo, procurar relacioná-lo com a realidade. As respostas eram dadas, entusiasmadamente, por todos os alunos:

Prof. ${ }^{a}$ - Então, há um lugar que já não conta que vai ocupado pelo chofer. Se um lugar vai ocupado com o chofer, esse carro só leva quantas crianças lá dentro?

Vários alunos- 4

Manuel- Não! 3. O pai do Tomás vai sentado ao lado do senhor que vai a conduzir.

Mónica- O pai do Tomás vai noutro carro.

Prof. ${ }^{a}$ - Então o pai do Tomás vai num carro. Já temos um carro. Quantas crianças é que ele leva nesse carro?

Flávio- 4.

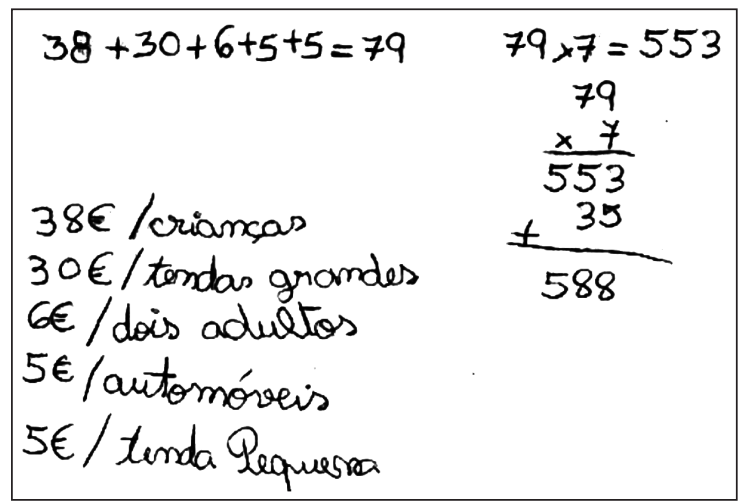

Figura 4 -Estratégia utilizada pelo grupo em foco para resolver o problema matemático que criou 
Enquanto a maioria dos alunos da turma continuava a demonstrar alguma passividade, alguns surpreendiam com a sua capacidade de iniciativa e espírito de descoberta. Mara foi uma delas, ao lembrar-se que se deveria acrescentar ao total da resposta dada pelo grupo, o valor a pagar pelos automóveis a alugar para transportar todas as crianças, conforme a lei. Era evidente que o gosto em descobrir algo de novo se estava a fomentar:

Mara- E mais os carros que faltam!

Prof. ${ }^{\text {- }}$ - Explica-te melhor.

Mara- Dois carros é 2 euros em cada dia...

Daniel- ... agora vezes porque é 7 dias. Dá 14 euros mais.

Para finalizar a atividade, Ana valorizou o facto de, em conjunto, podermos trocar ideias e chegar a uma resposta muito mais completa que sozinhos. Era evidente que se referia tanto ao benefício do trabalho em grupo, como à partilha de ideias na discussão dos resultados obtidos nesses grupos.

\section{A concluir}

A análise das duas aulas de resolução de problemas, referidas neste artigo, mostra que as interações na sala de aula, durante a atividade, não decorreram sempre do mesmo modo, variaram com a forma como foi feita a abordagem da resolução dos problemas e, consequentemente, com os intervenientes em cada uma das partes da atividade pedagógica.

A comunicação das ideias matemáticas, entre os intervenientes, durante as duas atividades, desenrolou-se, principalmente, através da linguagem oral. A linguagem escrita, no caso da resolução da primeira tarefa, circunscreveu-se aos registos elaborados pelos alunos e à resposta dada sob a forma de frase. No caso da segunda tarefa, todos os grupos usaram a escrita, quer na formulação dos problemas quer nas suas resoluções, verificando-se, contudo, a tendência generalizada dos grupos para utilizarem a linguagem simbólica da matemática, evitando usar a linguagem natural para ajudar à compreensão dos símbolos, apesar de terem tido a oportunidade de se servirem de diferentes representações e de se familiarizarem com elas.

A apresentação e introdução dos problemas, pela professora a toda a turma, constituiu o que se considerou a primeira parte das atividades pedagógicas e foi feita através de interações verticais, em que houve regulação da participação dos alunos, traduzindo-se num diálogo professora-aluno. Atitudes semelhantes 
foram também observadas por Veia (1996). Estas interações desenvolveram-se através da exposição e do questionamento aos alunos, por meio de perguntas de focalização e de confirmação fechadas e de resposta curta. As perguntas realizadas permitiram a interpretação dos enunciados e a partilha do significado de expressões menos usuais, necessárias à compreensão do problema. Apesar de muitas vezes essa partilha parecer não ter sido suficiente para o desenvolvimento da fase seguinte da resolução, no caso do primeiro problema e para o grupo em foco, isso não foi motivo para desinteresse, pelo contrário, os alunos evidenciaram firmeza e dedicação.

Quanto às interações aluno-professora, elas verificaram-se como consequência das perguntas colocadas pela professora. Em relação às interações horizontais, elas não se confirmaram na primeira parte da atividade. Em suma, as interações comunicativas que se verificaram nesta parte da atividade, e que partiram todas de Ana, parecem ter desenvolvido nos alunos a capacidade de aprender a ouvir - ouvir o colega e ouvir a professora.

Já na segunda parte das atividades, ou seja, na resolução dos problemas pelo grupo em foco, verificou-se uma menor intenção de controlo por parte da professora e um papel mais activo dos alunos, com grande número de interações horizontais. Estas visaram o estabelecimento de planos de resolução para os problemas propostos e a execução desses planos e tiveram como suporte a partilha de ideias, a distribuição de trabalho, os pedidos de esclarecimento relativos aos registos, os pedidos de confirmação de ideias, o questionamento como forma de seguir um raciocínio, os pedidos de ajuda, a ajuda ao semelhante e a crítica às ideias do outro. Apesar dos conflitos existentes no grupo, notados e já assinalados, Sara e Daniel estabeleceram entre si, na resolução da segunda tarefa, interações que os levaram a realizar um trabalho que favoreceu os dois, o que está de acordo com os resultados obtidos por César (1999).

Nesta segunda parte, também se puderam verificar interações verticais, realizadas por meio de perguntas de focalização e de confirmação. Partiram, sempre, da professora, e permitiram aos alunos quer o completamento das resoluções quer a verificação das soluções ou, ainda, a interiorização de procedimentos. Um exemplo dessa última situação foi o questionamento feito a Daniel na resolução do segundo problema. Foram também realizadas algumas perguntas de inquirição, onde era dado a conhecer o modo como os alunos tinham encontrado determinada solução e que serviam como ponto de partida para os ajudar a reflectir sobre os seus raciocínios e a negociar os significados dos seus registos, para além de confirmar o resultado. Este tipo de perguntas 
parecem poder influenciar o envolvimento do grupo na verificação dos passos dados e, em simultâneo, proporcionar momentos de partilha e negociação de significados. Estas ideias vão ao encontro das sublinhadas por Bishop e Goffree (1986).

A terceira parte da atividade, a comunicação e discussão dos caminhos ou estratégias encontrados por cada grupo, em plenário de turma, revelou-se um momento causador de algum embaraço e muita insegurança para alguns alunos, mas, também, de muito prazer para outros. Por exemplo, Sara, Bela e Tomás do grupo em foco, chegaram a manifestar o desejo de não apresentar o seu trabalho por se sentirem acanhados em expor as ideias à turma.

Outros, como Manuel e Mara, viveram esse momento com bastante entusiasmo, por gostarem de mostrar as suas descobertas. Nesta parte da atividade verificou-se, de novo, um grande número de interações verticais. De assinalar que não foi fácil encontrar a maneira de realizar a discussão dos trabalhos realizados na resolução de problemas com os alunos. A verdadeira discussão foi praticamente nula, pois os alunos revelaram não ter o hábito de interpelar os colegas acerca do trabalho apresentado, nem de o defender, mostrando-se pouco participativos. Assim, a comunicação resumiu-se à exposição do porta-voz do grupo para toda a turma, muitas vezes acompanhada de perguntas de confirmação da parte da professora para ajudar os alunos a interiorizarem as ideias e a ganharem mais confiança em si.

No entanto, quando foram chamados pela professora a verificar soluções, os alunos revelaram-se muito motivados para analisar os resultados exibidos e, ainda, para os criticar, contribuindo para isso, questões como: - o que é que se passa agora? -, ou: - ora vejam lá, quantas pessoas pode levar cada carro. Não obstante, ficou saliente a importância atribuída às interações verticais na sala de aula como forma de promover a aprendizagem dos alunos. Porém, parece-nos evidente que as interações comunicativas fomentadas entre os alunos não parecem ter a dimensão e a importância que lhe vêm sendo atribuídas pelas orientações curriculares para o ensino da Matemática (DEB, 1990; ME, 2007), ou os estudos realizados por César (1999), indo, assim, ao encontro dos resultados obtidos por Vieira (1997).

Assim, poder-se-á concluir que as interações foram decisivas para: i) o envolvimento dos alunos nas atividades; ii) a criação do espírito investigativo nos alunos; iii) o desenvolvimento da capacidade de comunicar dos alunos. Estas conclusões evidenciam a necessidade de uma reflexão sobre o tratamento destas questões na formação contínua, a fim de possibilitar aos professores do ensino 
fundamental um melhor entendimento acerca da comunicação como metodologia de ensino e como capacidade matemática a desenvolver na sala de aula e das implicações que daí resultam para a aprendizagem da Matemática.

\section{Referências}

ABRANTES, P. Viagem de ida e volta. Lisboa: APM, 1988.

BISHOP, A. J.; GOFFREE, F. Classroom organization and dynamics. In: CHRISTIANSEN, B.; HOWSON, A. G.; OTTE, M. (Eds.). Perspectives on mathematics education. Dordrecht: D Reidel, 1986. p. 309-365.

CÉSAR, M. Interacções matemáticas e apreensão de conhecimentos matemáticos. In: ESCOLA DE VERÃO PORTUGUESA - ITALIANA-ESPANHOLA, 1., 1999, Santarém. Actas... Lisboa: Secção de Educação Matemática da SPCE, 1999. p 5-46. CD-ROM.

DEB. Organização curricular e programas. Lisboa: Ministério da Educação, Departamento da Educação Básica,1990.

FERNANDES, D. M. Educação Matemática no 1. ${ }^{\circ}$ Ciclo do Ensino Básico: aspectos inovadores. Porto: Porto Editora, 1994.

FONSECA, L. Problemas com aparatos. In: FERNANDES, E.; MATOS, J. F. (Ed.). Actas do ProfMat 2000. Universidade da Madeira: APM, 2000. p. 311-325.

GUERREIRO, A. M. C. Comunicação no ensino-aprendizagem da Matemática: Práticas no 1. ${ }^{\circ}$ ciclo do ensino básico. 2011. 471f. Tese (Doutorado em Educação, Didática da Matemática) - Instituto da Educação, Universidade de Lisboa. Lisboa, 2011.

LAMPERT, M.; COBB. P. Communication and language. In: KILPATRICK, J.; MARTIN, W. G.; SHIFTER, D. (Eds.). A research companion to Principles and standards for school mathematics. Reston, Va: NCTM, 2003. p. 237-249.

MAMEDE, E. O papel da calculadora na resolução de problemas: um estudo de caso no 1. ${ }^{\circ}$ Ciclo do Ensino Básico. 2001. 200f. Dissertação (Mestrado em Supervisão) Instituto de Educação e Psicologia da Universidade do Minho, Braga, 2001.

ME. Programa de Matemática do Ensino Básico. Lisboa: Ministério da Educação, 2007.

PONTE, J. P. Investigação sobre investigações matemáticas em Portugal. Investigar em Educação, Lisboa, v. 2, s/n, p. 93-169, 2003. 
PONTE, J. P. Problemas e investigaciones en la actividad matemática de los alunos. In: GIMÉNEZ, J.; SANTOS, L.; PONTE, J. P. (Coords.). La actividad matemática en el aula. Barcelona: Editorial GRAÓ, 2004.p. 25-34.

PONTE, J. P. A gestão curricular. In: GTI (Coord.). O professor e o desenvolvimento curricular. Lisboa: Associação de Professores de Matemática, Grupo de Trabalho de Investigação, 2005. p. 11-34.

PONTE, J. P. et al. Histórias de investigações matemáticas. Lisboa: Instituto de Inovação Educacional, 1998.

PONTE, J. P.; SERRAZINA, M. L. Didáctica da Matemática do 1. Ciclo. Lisboa: Universidade Aberta, 2000.

RIBEIRO, D. A resolução de problemas e o desenvolvimento da comunicação matemática: um estudo de caso no 4 . $^{\circ}$ ano de escolaridade. 2005. 261f. Dissertação (Mestrado em Educação, Metodologia do Ensino das Ciências (Matemática)) Faculdade de Ciências, Universidade de Lisboa. Lisboa, 2005.

SKOVSMOSE, O. Cenários para Investigação. Bolema. Rio Claro, v. 13, n. 14, p. 66-91. 2000 .

VEIA, L. A resolução de problemas o raciocínio e a comunicação no $10^{\circ}$ ciclo do ensino básico: três estudos de caso. 1996. 237f. Dissertação (Mestrado em Educação, Metodologia do Ensino das Ciências (Matemática)) - Faculdade de Ciências, Universidade de Lisboa. Lisboa. 1996.

VIEIRA, G. M. O desenvolvimento profissional dos professores do 1. ${ }^{\circ}$ ciclo na área da matemática: três estudos de caso no contexto de um trabalho colaborativo. 1997. 313f. Dissertação (Mestrado em Educação, Metodologia do Ensino das Ciências (Matemática)) - Faculdade de Ciências, Universidade de Lisboa. Lisboa. 1997.

WOOD, T.; MERKEL, G.; UERKWITZ, J. Criar um ambiente na sala de aula para falar sobre a matemática. Educação e Matemática, Lisboa, v. 40, s/n, p. 39-43, 1996.

YACKEL, E.; COBB, P. Sociomathematical norms, argumentation and autonomy in mathematics. Journal for Research in Mathematics Education, Reston, Va, v. 27, n. 4, p.458-477, July 1996.

Submetido em Fevereiro de 2012. Aprovado em Maio de 2012. 
ISSN (versão impressa) 0104-9739

ISSN (versão eletrônica) 2176-2988
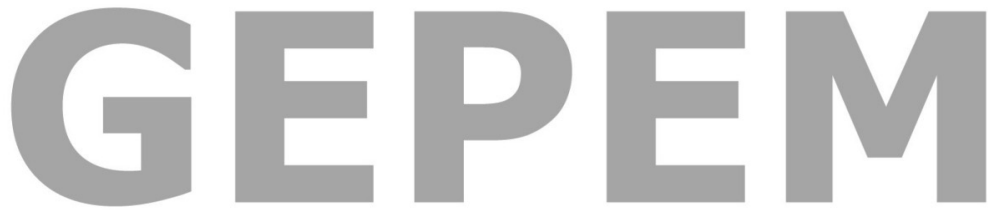

GRUPO DE ESTUdOS E PESQUISAS EM EDUCAÇÃo MATEMÁtICA
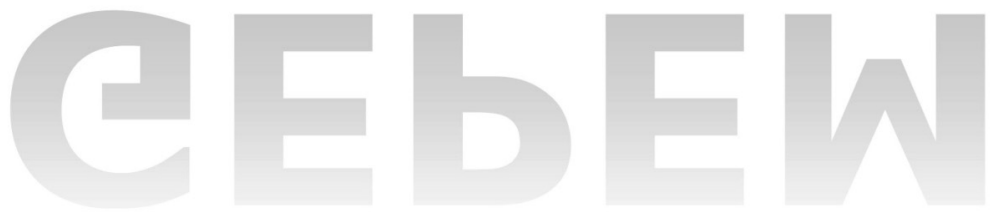

\section{Boletim Gepem}

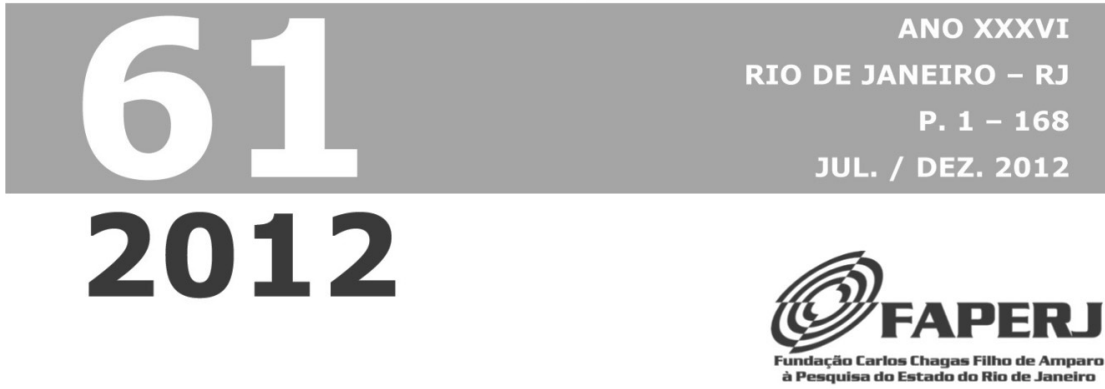

